\title{
An Exploration of Self-Love, Self-Annihilation, and Faith in Pascal's Pensées
}

\author{
Jia-Ying YU \\ St. John's College, Annapolis 21401, U.S.A. \\ yujia96@163.com
}

Keywords: Pascal, Self-love, Self-annihilation, Faith.

\begin{abstract}
In the Pensées, Pascal introduces the idea of the imaginary self-versus the real self. He states that it is impossible for us to love the substance of a person's soul, and it would also be wrong to do so. Our inability to find the essence of the soul is attributed to our corrupted nature, while the wrongness is ascribed to our pride of trying to transgress the natural order. After proving the emptiness of self-love, it is then necessary for us to look at the essentiality of self-annihilation, which, according to Pascal, is not the same as self-destruction but a healthy way of living life. Unlike Thomas Aquinas, who believes that there is a balance between maintaining the private self and submitting ourselves to God, Pascal thinks that the two are inherently contradictory, and the only way to solve the problem is to annihilate ourselves. He equates self-annihilation to faith and explains that there is no end to this self-annihilation but a constant practice.
\end{abstract}

\section{Introduction}

In the Pensées, Pascal repeatedly emphasizes the necessity of examining the truth about who we are as human beings in order for us to rightly understand what God means to us. According to the path he presents to us, recognizing the truth about our nature will lead us to the realization of the vanity of self-love and the essentiality of self-annihilation. However, how does self-love, which we normally believe to be the thing that supports us to live on in this world, turn out to be harmful to us? And how does self-annihilation, which always comes along with a dreadful hatred toward the self, manage to lead us to the belief in God rather than self-destruction? By first looking at what the "self" is, and then analyzing the relationship between self-love and self-annihilation, along with the question of truth and faith, we may be able to understand more about what Pascal means by believing in God and how it changes our perspective and our way of living life.

\section{Definition of the "Self"}

In our daily life, we often encounter the question of "who this person is." To answer it, we naturally and unconsciously go on describing what he looks like, what his character is, and what he has done in the past, without stopping to think how our answer never sufficiently addresses what makes this person a unique individual. In Pensée 688, Pascal defines these different aspects of a person as only his qualities but not the self. We usually regard a person as an aggregate of these various components and never try to abstract a substance from them. Pascal attempts to peel off these qualities of the self from outside in and look for what is lying in the center of it. After searching inside both the body and the soul and taking away appearance, judgment, and memory, since all of them can be changed without the self-changing, he finds out astonishingly that there is nothing left there:

Where then is this self, if it is neither in the body nor the soul? And how can one love the body or the soul except for the sake of such qualities, which are not what makes up the self, since they are perishable? Would we love the substance of a person's soul, in the abstract, whatever qualities might be in it? [1]

Pascal asserts that not only is it not possible to love the substance of a person's soul, but also it would be wrong. 
Why is it impossible for us to love someone as he truly is? And in what sense is it wrong? The fact that we can discover nothing at the center of our soul does not necessarily demonstrate the non-existence of an essence but might in fact indicate its inaccessibility. Thus the impossibility for man to love the substance of another's soul can be attributed to our blindness and inability to see it. We always look down upon those people who value their position and property too much, for we know that they are only attached to people temporarily, but we are never aware that those qualities we regard as more stable and meaningful, such as our memory, our knowledge, our judgment, and our personality, are in fact perishable as well. We grasp them as hard as we can, as if a substance is being derived out of them, without realizing that they are the layers and layers of packaging paper wrapped outside the center of our soul and can be easily torn away as well.

\section{Man's Position in Nature}

What are we supposed to do then, after recognizing the transient nature of these superficial qualities? Should we try to fix it and save ourselves from this miserable condition, at least as best as we may be able to? Pascal responds, not only is it impossible, but also it would be wrong for us even to go on to try to solve the problem in this way. He uses the word "injuste" in French, which means unfair, unjust, or wrongful, saying that it would be unjust if we think we would be able to love the substance of a person's soul, despite whatever qualities might be in it. In what way is this unjust? It is obvious that this love does not violate any moral justice, but does there exist some higher criterion that it might be transgressing?

There are laws within the human race, telling us how we should interact with each other. Similarly, there exists some higher order outside the human, concerning how we connect to other kinds of beings, namely, God and animals. It is likely that here Pascal is talking about the breaking of this higher order rather than an earthly justice. In Pensée 121, Pascal asserts, "Man must not be allowed to believe that he is equal either to animals or to angels, nor to be unaware of either, but he must know both." [1] In this statement, man is put in between angels and animals. A perfect balance is attained with the three of them staying in their proper positions. However, in thinking that he knows more and thus deserves to go higher, man refuses to stay where he should be and always wants to surpass the higher being. This dissatisfaction with our proper place in nature brings about our pride, and it is this same pride that makes us think we are capable of seeing and loving the substance of a person's soul. Animals do not have any knowledge of their individual self and never strive to think about it, whereas angels are not hindered by the exterior and see things through their essence. In thinking ourselves too allied with animals, we would be desperate, but in thinking ourselves too akin to angles, we would be prideful. The only way to understand where humans are in the order of nature is by putting ourselves in comparison with both angels and beasts and recognizing the differences.

There are two difficulties hidden behind this particular type of self-awareness. First, in order to find our true position, we always need to look at both directions simultaneously, whereas it is our nature to only stare at one direction at a time, due to our short-sightedness in understanding ourselves as part of the larger spectrum of created beings. As Pascal points out in Pensée 678, "Man is neither angel nor beast, and it is unfortunately the case that anyone trying to act the angel acts the beast." [1] Putting this statement back in the context of Pensée 688, if someone claims that he loves the substance of another person's soul, he might have been driven too far on the scale by his pride in thinking that he alone is intelligent enough of doing what only God can do. It is due to this limitation of how we perceive and comprehend things that we always end up getting too close to one extremity of the spectrum and misplace ourselves on the hierarchy of angel, man, and animal.

The second difficulty lies in the fact that learning who we are through who we are not gives us a merely negative knowledge of ourselves. It is a knowledge we do need to acquire, but it will not entirely solve the problem for us, since knowing how we are different from angels and animals does not give us any substantial insight of who we truly are but can only help us locate ourselves on the scale. Instead of presenting us the essence, it only tells us about our location. 
It is also worth noting that Pensée 688 talks about the self only from the viewpoint of how other people perceive us and how we perceive others rather than how we look at ourselves. Is it more difficult to answer the question of "who I am" than "who somebody else is?" One question is not harder than the other in the abstract; we are equally unable to articulate the essence of someone else's soul as our own. However, it feels easier for us to accept the fact that we cannot know other people accurately, but we all tend to be confident that we have a more profound and complete understanding of ourselves. It bothers us more to be unable to access ourselves. Is it in fact also an illusion that we think we do know ourselves? In Pensées 113 and 200, Pascal uses the reed analogy to describe the disposition of a human. Although there the aim of the analogy was to show how we could only comprehend the world through our thoughts, the image of the reed can be equivalently applied to what we are discussing here as well. How does a reed perceive itself? When the wind blows, it bends with the wind; when the water flows, it floats with the water. Without having any definite form, its nature changes in accordance with the external circumstances. Thus when a reed says, "I know myself," it is likely that what it knows is not the substantive form but a temporal figure shaped by the outside environment. Likewise, when I say, "I know myself," the "myself" stands for nothing but a temporal "me" molded by the exterior forces.

\section{The Imaginary Self}

Now, if we admit that we are actually ignorant of who we are but still believe that we know how to love ourselves, what then could the object of this love be? Pensée 978 addresses the problem of self-love and reveals the self-contradiction hidden behind this love. One thing that immediately draws our attention about this pensée is that Pascal uses the pronoun "it" instead of "I" or "we" to refer to the "self," or, even more puzzling, to the "self-love" itself. Instead of asking "what can we do," he questions, "What is it to do?" Instead of saying "we want to be great and see that we are small," he states, "it wants to be great and sees that it is small." [1] The disjunction between "it" and "us" suggests that this object we find and we love might not even be the real self that stands for who we are but a fake image we rely on in order to deceive and numb ourselves. Pascal personifies the self-love by using a separate third-person pronoun and making it into its own being, which suggests that this illusory self goes on taking over the power and even acquires some active agency by itself.

Why do we need to attach ourselves to an imaginary object in the first place and try to persuade ourselves that it is the truth? Pascal writes in Pensée 978, "it (the self-love) conceives a deadly hatred for the truth which rebukes it and convinces it of its faults. It would like to do away with this truth, and not being able to destroy it as such, it destroys it, as best as it can, in the consciousness of itself and others." [1] Almost ironically, the self-love places itself against the truth about the self. This seeming love turns out to be a hatred, a hatred toward the truth that we are "nothing but disguise, falsehood and hypocrisy." [1] It is because we cannot face up to this truth that we have to rely on an imaginary self to comfort us.

In addition, the self-love and the truth have a more complex relationship than simply standing in opposition to each other from afar. In the quote above, the truth "rebukes" the self-love and "convinces" the self-love of its faults. The language of rebuking and convincing suggests that there is some interaction going on in between them, however, not taking the form of a harmonious and pleasant conversation, but as confrontation. Strangely, Pascal only emphasizes this conflict between the self-love and the truth, while the actual self is not brought in as an active participant of this interaction yet has faded away from the picture. How are self-love and truth in a conversation with each other? And why is the actual self not in this scene?

We have all experienced those "aha" moments when we are doing math propositions, when the truth suddenly enters our awareness and fills up the "I." Here, the same image might be used to help us understand the relationship among the actual self, self-love and truth, yet in a very different way. When the self-love and the truth are at odds with each other, this tension between them is so whelming that it takes over the position of the actual self. The "I" is swallowed up by the sharp 
conflict. However, although there is a disappearance of the self in both the case of math proposition and the case of self-love, we have to make clear the difference between them. In the former, a higher unity is achieved with the fading of the "I," whereas in the latter, there is constantly a confrontation. This perpetual confrontation always conveys struggle and unease, overpowering the self and making it impossible to settle down.

Therefore the question is no longer why we create a fake image for ourselves, since self-love is not something we create and have control over, but is in fact an actual force which functions regardless of whether we are aware of it or not. Instead, we should ask: What is it that makes this confrontation so acute and distressing that it becomes an irreconcilable battle without end? In order to answer this question, let us look back at the corruptness of our nature Pascal illustrates in Pensée 978. Pascal uses the words "défaut," "misère," and "imperfection" to refer to the defects rooted in our nature. Their respective meanings in English are default, misery, and imperfection, which all point to some actual deficiency in our inherent nature which disallows any possibility for us to repair or modify. In contrast with the errors and mistakes we make in our daily life and the sins we commit, in which we can still see a hope of improving and bettering ourselves, the defects Pascal talks about in Pensée 978 have no remedy. It is a constant struggle for us to try to face up to these defects.

\section{The Necessity of Self-Annihilation}

But there does exist one kind of medicine, according to Pascal, that can be taken by self-love. However, instead of cleansing and curing it, this medicine in turn kills the self-love. According to our daily experience, the patient takes the medicine, while the medicine helps the patient to recover by killing the virus in his body. In contrast with how medicine normally works, here we have the self-love being both the patient and the virus, both the one who needs to take the medicine and the one who needs to be killed. The only way that the self can be healed is by self-love killing itself. However, "even then such medicine still tastes bitter to self-love, which takes as little of it as possible, always with disgust and often even with secret resentment against those administering it." [1] Being unable to destroy itself, the self-love tries to destroy the truth, the one who reveals to it of its despicable nature. This is the primary reason why self-love is inseparable from hating the truth in the first place.

Here come two of the most critical questions concerning self-love and self-annihilation: why is it necessary to kill self-love? And why is it so hard? Imagine ourselves sitting in an empty room alone with nothing to do but thinking about who we are and what we do every day. Almost inevitably, we will start to question ourselves, for everything we do in our daily life begins to lose its original meaning. We will start to panic, not because of what we did wrong in some particular circumstance in the past, but because of the meaninglessness in our daily concerns and actions. Why do we care about being virtuous in front of people? Why do we strive to be outstanding and different from others? Why do we want to be lucky and happy? We cannot stand contemplating these questions for very long and will soon turn away from them to find something easier and more pleasing to think about, for astonishingly, we could not even come up with an answer for these questions, or, we are in fact scared of seeing the true answer. Pascal says in Pensée 133, "Being unable to cure death, wretchedness and ignorance, men have decided, in order to be happy, not to think about such things." [1] The more we try to cover up this truth by diverting ourselves from it, the more it proves its strength and exposes our weakness and helplessness. However, the question still remains, why should we face up to the truth and annihilate ourselves? Why could we not just as well say we "should" divert ourselves from such an unpleasant truth, pretend we are good, and thus be happy?

Another way to approach the same question is by asking, what is so malicious and terrible about our pride, if it does not seem to really hurt our body or our feeling? Earlier, when talking about Pensées 121 and 678, we came to the conclusion that putting ourselves too close to the angels makes us prideful, and putting ourselves too close to the beast makes us desperate. The fact is, in our real life, there are always far more people who are prideful than those who are desperate, because pride does not cause us any perceivable pain, but desperation does hurt us. How can we describe those people 
who are prideful? Either that they are still blind to the truth about their corrupted nature or that they have seen this truth, yet they can simply choose to turn away from it. But what does "seeing the truth" mean in the second part of this account? Do we indeed have any license to choose after we actually see the truth?

Before we go on to answer these questions, it might be helpful to distinguish the different categories of truth. Firstly, there are truths that are tangible to us and easy for us to reason or act in accordance with, such as those facts and propositions we have discovered in the field of mathematics and science. Once we have learned that two plus three equals five, or that the product of the base and the height of a triangle gives us twice the area of that triangle, it becomes impossible for us to conceive of any alternative case. Secondly, there are truths that are possible for us to see but always require effort in order for us to follow them or sometimes are even impossible to keep up with them. For instance, we might be temporarily persuaded by the truth about the inaccessibility of any substance of our soul, but we are not capable of living our life with this idea in mind all the time. Thirdly, there still remain some other truths, which are impossible for us to even see except through the help of faith. The truth that there is only one way we could go, which is to annihilate ourselves, falls into this last category. In fact, Pascal wants to offer a higher position to these truths that require faith rather than analysis by making a distinction between the truths felt by our heart and those acquired through our reason. He comments in Pensée 110, "We know the truth not only through our reason but also through our heart. It is through the latter that we know first principles, and reason, which has nothing to do with it, tries in vain to refute them." [1] Impossible to be proved or disproved by reason, it is a truth supported by faith that the only path we have is to annihilate ourselves, just as Pascal himself says, "The heart has its reasons of which reason knows nothing." [1]

There is one thing in common about these three categories of truth just mentioned, that there is some absolute actuality in all of them, which, having seen it, there is no room for us to doubt or back out. We might be incapable of keeping up with its standard, but still we have no agency to actively negate it. Therefore, anyone who thinks that he sees the truth but claims that there is still an alternative for him to choose has not truly seen the truth. Anyone who sees the necessity of self-annihilation through faith will not be able to consider diversion as an alternative solution.

Before we move on, we should explicate more clearly why faith and self-annihilation are put together in the first place. In Pensée 378, Pascal associates faith with hating the self:

True conversion consists in self-annihilation before the universal being whom we have so often vexed and who is perfectly entitled to destroy us at any moment, in recognizing that we can do nothing without him and that we have deserved nothing but his disfavor. It consists in knowing that there is an irreconcilable opposition between God and us, and that without a mediator there can be no exchange. [1]

The proper way to annihilate ourselves is by negating ourselves in front of the universal being and admitting that we are nothing without him. Annihilating ourselves with God in mind is different from destroying ourselves indiscriminately. Here the emphasis is on the change of perspective. Earlier we have shifted our perspective from having only ourselves in the picture and considering ourselves as the entity, to the image of a lever, where we look at both the angels and the beasts to locate where we are on the scale. Now, here is another shift in perspective: We should conceive ourselves as one of the many members of a greater body, or as a single atom in the vast universe, which are beings that have no real existence unless we bear the whole picture in mind.

\section{The Relationship between Individual Beings and the Greater Whole}

Let us look closer at the atom analogy and see if it can help us further understand our relationship with God. In the beginning, we all believe that as atoms, we are individual beings independent of others and are somehow in control of our own movement. We feel like possessing a real material center, from which emanates our own power. With this illusion that we are the very source of our movement and our power, we regard ourselves as self-sufficient. Pascal first takes away the material center from 
the picture, by proving to us the inaccessibility of the substance of our soul. If we are incapable of seeing any essence in us, we should not be thinking that there exists any tangible center except only some force. It is simply this force but not any substantial core that is holding all our qualities together. If we imagine the force ceasing to exist, the self will be disintegrated and the qualities scattered away. We might then think, even though we do not own any material center, at least we could be the source of our own force. However, Pascal goes on claiming, even this force does not belong to us in the first place either. We are not the creator of our force but the receiver of it, for God has bestowed different forces among all, and the force each individual atom ends up having is simply a resultant force from the greater forces. Having faith is to realize our position in front of God, and with this picture in mind we would no longer be able to love ourselves as if we still have any agency.

In order to illustrate the same thing more vividly and better explain what annihilating the self means, Pascal uses the image of the foot and the body in Pensée 373 to represent the relationship between each individual self and the whole. In this analogy, the whole is considered as the body, while man is the foot. We always take pride in our own existence and delight in the power we have as a foot, but fail to recognize that the foot could not even be a foot without the body endowing it with some purpose in the first place. If a foot alone does not have any beauty or functional faculty, what makes it possible for us to appreciate the existence of a foot? It is by putting it in the picture of the entire body. As Pascal says in Pensée 372, "To be a member is to have no life, no being and no movement except through the spirit of the body and for the body." [1] In this sense, self-annihilation does not mean to purposelessly destroy ourselves and give up our life, but rather means to realize our dependence on God and submit ourselves to Him. It is only through this submission and this forsaking of our individuality we could find the true meaning of our existence.

Suppose if we could live our life with this new perspective. Considering that we are now able to find the right position for us and seek for the real meaning of our life in the body of the whole, will it be possible that there arises a proper and moderate love that we can have toward ourselves, a love different from the illusory self-love we talked about earlier? Pascal does bring back some room for a proper love toward the self, "In order to control the love we owe to ourselves, we must imagine a body full of thinking members (for we are members of the whole), and see how each member ought to love itself." [1] Therefore, there indeed is a reasonable and healthy way for us to love ourselves, through viewing ourselves as parts of the whole and as members of Jesus Christ.

We should be careful not to picture everything in a too optimistic way and hastily conclude that we have now reconciled the problem of self-love and self-annihilation. Different from most philosophers in history, who usually search for a balance between the individual beings and the greater whole by trying to present us both the necessity to submit to the greater whole and the importance to maintain some individuality within ourselves, here Pascal tends to negate the last bit of the individuality one can have and wants us to fully submerge into the greater whole. It is true that there does exist some positive way that we could think about the being of the foot, that it can help the body walk, or that it can do something that the other parts of the body cannot do. But is this distinctiveness that the foot has enough to provide any evidence of its actual individuality? Pascal is more likely to give a negative answer to this question. Pensées 135 and 373 might be able to show us more about Pascal's attitude toward this problem of to what degree we should annihilate ourselves: "I who think would never have been if my mother had been killed before I had come to life; therefore I am not a necessary being. I am not eternal or infinite either, but I can see that there is in nature a being who is necessary, eternal, and infinite." [1] "Every member must be willing to perish for the sake of the body, for whose sake alone everything exists." [1] According to Pascal, the full submission to God requires an absolute negation of the self. However, it is reasonable for us to ask: Is this absolute negation actually possible for human beings? Pascal never gives a clear answer to this question. The fact that he wishes us to annihilate ourselves yet cannot get away with it except through repeatedly asserting the same thing about the vanity of self-love and the necessity of self-annihilation in turn proves the great difficulty or even the impossibility of this absolute negation. 


\section{Conclusion}

According to the theory Pascal presents us, we should not be thinking that there is any easy and smooth path we could find or any explicit and detailed checklist we could follow. We might mistake ourselves in reasoning that there are certain steps that can lead us to the final salvation: the first step is to realize our incapability of seeing the essence of our soul; the second step is to get rid of our self-love and annihilate ourselves; and the third step is to finally submit ourselves to God. Pascal will not think this is the way in which things could work out, since the fact is that, in real life, all these steps are mixed and intertwined together. We realize some truth but then get diverted from it. We sometimes see the necessity of annihilating ourselves but other times are drawn back by our self-love. It is an eternal endeavor that we have to constantly force ourselves to work on.

Although there is nothing we can do to fully keep ourselves from falling back to the original state again and again, does this eternal endeavor somehow grant us a new way to understand our life? We usually consider the meaning of life being consisted in us actively going out searching for something, attaining new things, and trying to improve ourselves. However, doesn't giving up something we thought we already have require a different and greater effort than trying to attain something? And isn't it more difficult to break an invisible chain than to break a tangible one? There is a kind of activeness in loosening one's grip of something we value highly and have grown dependent upon, and it might be this very thing that Pascal wants us to keep working on our entire life. Has Pascal himself "succeeded" in annihilating himself? Is writing the Pensées a way for him to humble himself and to work on his problems as well? Instead of a traditional philosophical work, Pascal presents us all the contents of his own meditation, doing the work he suggests all his readers to do.

\section{References}

[1]. Pascal B. Pensées. English trans. AJ Krailsheimer. Penguin, 1995 